EPJ Web of Conferences 18, 01002 (2011)

DOI: $10.1051 /$ epjconf/20111801002

(C) Owned by the authors, published by EDP Sciences, 2011

\title{
Observational astrochemistry: The quest for interstellar molecules
}

\author{
M. Guélin 1,2,a \\ ${ }^{1}$ IRAM, 300 rue de la piscine, 38406 St. Martin d'Hères, France \\ ${ }^{2}$ ENS-LRA/LERMA, 24 rue Lohmond, Paris, France
}

\begin{abstract}
Over 160 molecular species, not counting isotopologues, have been identified in circumstellar envelopes and interstellar clouds. These species have revealed a wealth of familiar, as much as exotic molecules and in complex organic (and silicon) compounds, that was fully unexpected in view of the harshness of surrounding conditions: vanishingly low densities, extreme temperatures and intense embedding UV radiation. They illustrate the diversity of astrochemistry and show robust prebiotic molecules may be. In this lecture, we review the quest for interstellar molecules and show how tributary it is from theoretical ideas and technology developments. A. A. Penzias, who discovered interstellar CO and the $2.7 \mathrm{~K}$ Cosmic Background radiation, used to joke that astronomical research is easy: the great questions have largely been formulated; one only has to wait until technological progress makes it possible to answer.
\end{abstract}

\section{THE FIRST STEPS}

The presence of diffuse gas between stars became clear some 100 years ago, when it was realized, in the course of spectroscopic studies of bright stars, that some absorption lines were too narrow to come from stellar atmospheres and must arise from a much cooler, low density medium: interstellar (IS) gas. Although most narrow lines were readily identified with electronic transitions of atoms, such as $\mathrm{Na}$, $\mathrm{Ca}, \mathrm{K}$ and $\mathrm{Mg}$, some, dubbed U-lines, eluded any assignment. It is only in 1937 that P. Swings and L. Rosenfeld tentatively assigned several U-lines between $388 \mathrm{~nm}$ and $430 \mathrm{~nm}$ to the diatomic radical $\mathrm{CH}$ [25]. Shortly later, Andrew McKellar [22] assigned two U-lines in the same wavelength range to a second radical, $\mathrm{CN}$; finally Douglas and Herzberg [8] assigned $3 \mathrm{U}-$ lines to $\mathrm{CH}^{+}$, after succeeding in forming this cation in an electric discharge and measuring accurately its spectrum. Interstellar molecules were born, although not yet interstellar chemistry.

It is worth noting that the discovery of the first interstellar molecules was made possible by the conjunction of two major advances: the construction of the 100 inch Hale telescope, which made high resolution spectroscopy possible, and the birth of molecular spectroscopy thanks, in particular, to Gerhard Herzberg (Fig. 1). In the next decades, such lucky conjunctions repetitively acted to enlarge the interstellar molecule zoo.

\section{RADIO TAKES OVER}

Twenty years elapsed before the next major step, which occurred thanks to the development of microwave spectroscopy and radio astronomy. The latter stemmed out of radar development during World War 2, particularly of the work directed by I.I. Rabi at the Columbia Radiation Lab where was

\footnotetext{
ae-mail: guelin@iram.fr
}

This is an Open Access article distributed under the terms of the Creative Commons Attribution-Noncommercial License 3.0, which permits unrestricted use, distribution, and reproduction in any noncommercial medium, provided the original work is properly cited. 


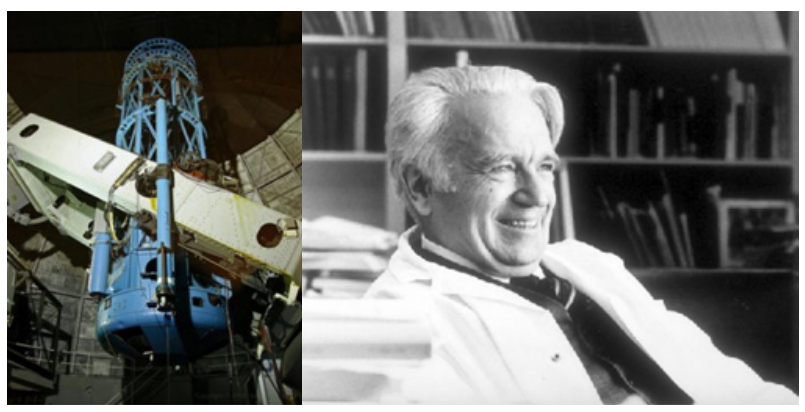

Figure 1. The 100 inch Mt Wilson telescope. Gerhard Herzberg, the Father of Molecular Spectroscopy, who identified with A.E. Douglas $\mathrm{CH}^{+}$as the carrier of interstellar U-lines discovered in the 1930's with this telescope. Photo: CNRC.

developed a tunable pulsating source operating in the $\mathrm{cm}$ wavelength range. In the late 1950's, under the impulsion of Charles H. Townes, such sources started to be used to study molecular spectra. It was understood (see Herzberg's book Diatomic Molecules) that radicals with an odd number of electrons, such as $\mathrm{CH}, \mathrm{CN}$ and $\mathrm{OH}$, have a non-zero angular momentum $\Lambda$ and/or a non-zero electronic spin $\Sigma$. The interaction of $\Lambda$ and $\Sigma$ with the magnetic field caused by the end-over-end rotation of the molecule backbone (and by the spin of its nuclei) splits the rotational levels into fine structure (fs) sublevels (and into hyperfine structure - hfs - sublevels) with slightly different energies. Transitions between those sub-levels give rise to low frequency transitions (few $\mathrm{GHz}$ ), observable with the radio techniques of the 1960's. The radio signature of $\mathrm{OH}, 4$ transitions near $1.7 \mathrm{GHz}(\lambda=18-\mathrm{cm})$ connecting $2 \times 2$ sublevels split by $\Lambda$-doubling and hf interactions, was characterized in the lab in 1963 and observed shortly after in dark interstellar clouds with the MIT Haystack radio telescope, a 37-m giant constructed for the tracking of the first artificial satellites ([29]).

Microwave studies of the ammonia molecule, $\mathrm{NH}_{3}$, revealed an interesting property of this symmetric pyramidal compound: inversion transitions. Because the ammonia molecule may tunnel between two forms symmetrical with respect to the plane of its 3 hydrogen atoms, its rotational levels are each split into two sub-levels of slightly different energies. Transitions between those sub-levels, although weak, are not forbidden and give rise to a line at $23 \mathrm{GHz}(1.2 \mathrm{~cm})$. This "inversion" line of NH3 was observed in the lab by Charles $\mathrm{H}$. Townes and his colleagues and detected in space in several interstellar clouds as soon as radio telescopes were capable of observing at such (at the time) a high frequency [5].

Beside electronic transitions that primarily occur at optical wavelengths and, for a few species, finestructure transitions observable at $\mathrm{cm}$ or $\mathrm{dm}$ wavelengths, molecules show vibrational and rotational radiative transitions. The former fall at IR and FIR wavelengths and the latter at $\mathrm{mm}$ or $\mathrm{cm}$ wavelengths. Contrary to electronic and vibrational transitions, rotational transitions correspond to small changes in energy and may be observed in emission in the cold interstellar gas. They are the best tracers of cold dense clouds and the best probes of their physical state and chemical content.

Water vapour, the v-shaped $\mathrm{H}_{2} \mathrm{O}$ molecule, is polar and has a wealth of rotational transitions, one of which that connects two levels with reasonably low energies has a wavelength of $1.3 \mathrm{~cm}$, close to the ammonia inversion transition. It was readily detected in the Orion A star forming region [6]. To close this chapter, formaldehyde, $\mathrm{H}_{2} \mathrm{CO}$, has two rotational levels close in energy that give rise to a line at $6 \mathrm{~cm}$. This line - the first line from an organic molecule - was detected in 1969 in dark clouds with the newly completed NRAO $140 \mathrm{ft}$ (45-m) telescope (Fig. 5) by Lewis E. Snyder, David Buhl, Ben Zuckerman, and Pat Palmer in 1969 [24].

At that stage, all small molecules, formed of abundant elements and having transitions observable with the radio telescopes of the 1960's, were detected in interstellar clouds: the stable species $\mathrm{NH}_{3}, \mathrm{H}_{2} \mathrm{O}$ 

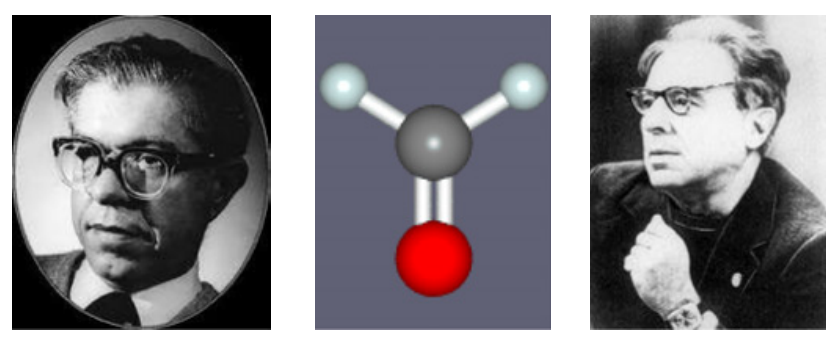

Figure 2. Left: Fred Hoyle, who predicted the presence of complex interstellar organic molecules in his 1957 science fiction book The Dark Cloud. Middle: Formaldehyde, the first polyatomic organic molecule was identified in space in 1969 by Lewis Snyder and co-workers. Right: Iossif Shklovsky.

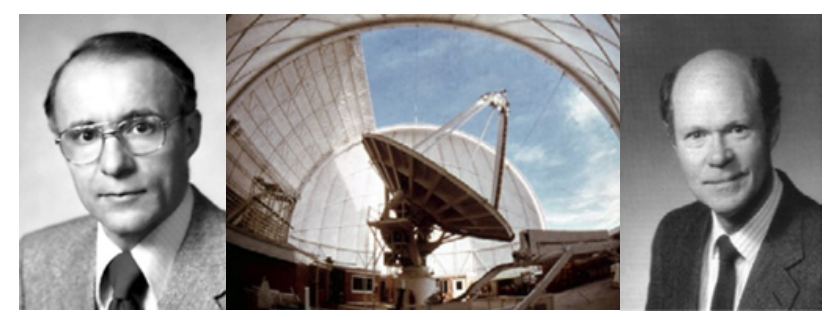

Figure 3. Penzias (left) and Wilson (right), who discovered, together with K. Jefferts, interstellar CO with the NRAO Kitt Peak telescope. The Kitt Peak telescope, the first "large" mm-wave telescope, helped to identify in the 1970 's a large crop of interstellar molecules and is still active today.

and $\mathrm{H}_{2} \mathrm{CO}$, the radicals $\mathrm{CH}$ and $\mathrm{OH}$, the ion $\mathrm{CH}^{+}$. This was unexpected as, for a long time, scientists doubted that any molecule, even $\mathrm{H}_{2}$, could survive in the harsh interstellar conditions. Only the renown astronomer Fred Hoyle suggested in his science-fiction novel "The Dark Cloud" [15] that organic molecules may hide in interstellar clouds, which would actually be living entities. I remember when theoretician Iossif S. Shklowsky, hearing about the discovery of interstellar formaldehyde, grumbled in a choppy, excited voice with a heavy Russian accent "Dark Cloud, the Dark Cloud!".

\section{3. $\mathrm{CO}, \mathrm{H}_{2}$ AND THE BIRTH OF INTERSTELLAR CHEMISTRY}

$\mathrm{CO}$ is the most stable molecule with non-zero dipole moment (a necessary condition for strong rotational transitions); it is formed of $\mathrm{C}$ and $\mathrm{O}$ the two most abundant cosmic elements, after $\mathrm{H}$ and $\mathrm{He}$. Irrespective of any chemical consideration, it was easy to predict after the discoveries of $\mathrm{CH}, \mathrm{OH}$ and $\mathrm{H}_{2} \mathrm{CO}$ that it should be ubiquitous in UV-shielded clouds and would be a good tracer of such clouds. Its lowest rotational transitions, the only ones collisionally excited in the cold gas, were known to be in the $\mathrm{mm}$ domain, the fundamental transition, $\mathrm{J}=1-0$, having a frequency of $115.3 \mathrm{GHz}(2.6 \mathrm{~mm})$. For some time, such a "high" frequency was out of the reach of radio telescopes. Arno Penzias, Robert Wilson and K. Jeffreys, working at the Bell Telephone Laboratories, together with Sandy Weinreb from NRAO, decided to build a heterodyne receiver capable of observing at this frequency and installed it on the brand new NRAO 36' telescope on Kitt Peak, the first 10-m class radio telescope with a surface accurate enough to observe at $3 \mathrm{~mm}$ wavelength (Fig. 3). Granted with 6 weeks of telescope time they observed for the first time $\mathrm{CO}$ in a number of astronomical objects [30].

Shortly after the discovery of interstellar CO, Gerard R. Carruthers was able to observe with a rocket-borne telescope the Ly $\alpha$ line of $\mathrm{H}_{2}$ in an interstellar cloud - the first detection of a molecule from space. The observation was made in absorption against the bright star $\zeta$ Per and yielded an $\mathrm{H}_{2} / 2 \mathrm{H}$ abundance ratio of $\simeq 1 / 2$. Even today, after many more absorption measurements against bright stars, the 


\section{EPJ Web of Conferences}

quasi-parity in the local gas between atomic and molecular phase seems still to hold. The $\mathrm{H}_{2}$ molecule is very light and has no permanent dipole moment; it is therefore difficult to observe its emission in the cold interstellar clouds. The lowest observable transition is a quadrupolar transition at $24 \mu \mathrm{m}$ that connects the $\mathrm{J}=2$ to the $\mathrm{J}=0$ rotational level. It took some 40 more years until this transition was detected and regular observations be made by the ISO satellite. Even so, the relatively high energy of the $\mathrm{J}=2$ level makes it difficult to estimate the column density of $\mathrm{H}_{2}$ in cold interstellar clouds. This is why the $\mathrm{H}_{2}$ column density is usually derived from the $\mathrm{CO}$ line intensities.

Besides $\mathrm{H}_{2}$ and $\mathrm{CO}$, the molecules expected to be the most abundant in the IS gas are diatomic molecules consisting of abundant second-row elements $(\mathrm{C}, \mathrm{N}, \mathrm{O})$ and their triatomic analogs with one hydrogen atom. As for $\mathrm{CO}$, the fundamental rotational transitions of those species occur near 3-mm wavelengths. The same applies to the $J=2-1$ transitions of the sulfur analogs, e.g. CS. By 1970, the most stable such molecules, those easily available in chemical shops, had been studied in the microwave $\mathrm{lab}$ and their rotational transition frequencies were known. After the discovery of interstellar CO, the scientists from the BTL group and co-workers had just to go down the list and try. HCN, CS, SO, $\mathrm{H}_{2} \mathrm{CS}$ and many more were so detected, which led Patrick Thaddeus to formulate the "Fisher Chemical Principle" (not to be confused with Fisher's Principle on sexuality): if it can be bought it at Fisher Chemicals, NY, NY, it's in space, and conversely. Interstellar space seemed boring: early microwave spectroscopists, mainly interested by the derivation of molecular structures, were mostly studying simple, stable compounds. At that time, radio astronomers couldn't less care about astrochemistry.

Chemists took their revenge shortly after. In 1970, Buhl and Snyder [2] while observing Orion A at 3-mm wavelength discovered two strong lines, U89180 MHz and U90665 MHz, that didn't match the lines of any catalog.

The first was quickly identified with the cation $\mathrm{HCO}^{+}$by William Klemperer and Eric Herbst. Herbst and Klemperer had just worked out a new theory for the formation of molecules in the cold and diffuse interstellar gas, based on ion-molecule reactions. Contrary to neutral-neutral molecule reactions, which have activation barriers, most ion-molecules reactions have no barriers and proceed at every collision in the cold IS gas. The theory predicted that molecular cations should be present in IS space and that $\mathrm{CO}$ and $\mathrm{HCO}^{+}$should be tightly connected through protonation and dissociative recombination. Protonation occurs during the reaction of $\mathrm{CO}$ with $\mathrm{H}_{3}^{+} . \mathrm{HCO}^{+}$, very reactive in normal conditions, had never been studied in the laboratory. From simple bond-length considerations and more sophisticated ab-initio quantum mechanical calculations of the geometrical structure, Klemperer showed that the fundamental $\mathrm{J}=1-0$ rotational transition of $\mathrm{HCO}^{+}$, the analog of the $\mathrm{CO} \mathrm{J}=1-0$ transition, had a frequency close to $89 \mathrm{GHz}$. The identification of $\mathrm{U} 89180$ carrier with $\mathrm{HCO}^{+}$was subsequently supported by the detection of its ${ }^{13} \mathrm{C}$ isotopologue, $\mathrm{HC}^{13} \mathrm{O}^{+}$, whose transition frequencies were predicted by isotopic-shift calculations; several years later, Claude Woods succeeded in fully characterizing the $\mathrm{HCO}^{+}$and $\mathrm{HC}^{13} \mathrm{O}^{+}$rotational spectra in an electric discharge, making a final confirmation. The second U-line U90665 MHz was similarly identified with HNC, an isomer of the stable and relatively abundant molecule HCN. Ion-molecule models were indeed showing that $\mathrm{HCN}$ forms from the dissociative recombination of $\mathrm{HCNH}^{+}$, which yields to both $\mathrm{HCN}$ and $\mathrm{CNH}$. Astrochemistry had made a giant leap forward.

Finally, to secure the (temporary) triumph of the new ion-molecule chemistry theory, a triplet of Ulines near $93170 \mathrm{MHz}$, with relative intensities in the ratio 1:5:3 was discovered in a number of sources. The 1:5:3 intensity ratio is the signature of quadrupole hyperfine structure caused by a nucleus with an electric quadrupole moment $\mathrm{Q}=1$, such as the nitrogen nucleus. The carrier was identified shortly later by [23] as the linear cation $\mathrm{NNH}^{+}$on the basis of the line frequency (twice the rotational constant for a linear molecule) and of the likely hypothesis that the $\mathrm{Q}=1$ nucleus was nitrogen. $\mathrm{NNH}^{+}$is isoelectronic with $\mathrm{HCO}^{+}, \mathrm{CO}$ and $\mathrm{N}_{2}$ and predicted in the ion-molecule theory to form by protonation of $\mathrm{N}_{2}$, just as $\mathrm{HCO}^{+}$forms by protonation of $\mathrm{CO}$. The identification of the triplet carrier with $\mathrm{NNH}^{+}$was confirmed by its observation in quiet dark clouds, where the Doppler-broadening of the lines is so small that the 
further splitting of each of the 3 main triplet components into 3 sub-components, caused by the presence of a second $\mathrm{N}$ nucleus at the center of the molecule, could be resolved.

\section{RADICAL TIMES}

The brillant identifications of $\mathrm{HCO}+$ and $\mathrm{HNC}$ with one single strong U-line from purely chemical considerations were not to be renewed (except perhaps, 15 years later, for SiC). No other such strong U-lines were afterwards detected, and the new molecular species identified without the help of lab frequencies had to be extracted from weeds of uninteresting U-lines, mostly originating from vibrationally excited states and rare isotoplogues of known molecules. This painful task usually calls for the recognition of characteristic line patterns linked to fs and hfs.

We have seen above that interactions between the electric field caused by the end-over-end rotation of a polar radical, $\mathbf{N}$, and the electronic angular momentum $\Lambda$ and spin $\Sigma$ of a radical (e.g. the $\mathrm{OH}$ and $\mathrm{CN}$ radicals) split the rotational levels into sub-levels. We are not considering anymore the weak, low frequency transitions between the sub-levels of a single rotational level (like the $18 \mathrm{~cm}$ lines of $\mathrm{OH}$ ), but the transitions between adjacent rotational levels, i.e. rotational transitions. Because of the presence of distinct sub-levels, each rotational transition is split into two or more components. The relative strengths of those fs components depend on the type of interaction $(\Lambda$ or $\Sigma$ ) and are fairly easy to calculate (See Townes and Schallow [27]). In the cases where the radical contains one or more atom with a non-zero nuclear spin (e.g. $\mathrm{H}$ or $\left.{ }^{14} \mathrm{~N}\right)$, further interactions cause more sub-level splittings leading to hyperfine structure (hfs).

In 1974, Barry Turner detected in OrionA and several other molecular sources a series of 6 fairly strong U-lines with frequencies close to $92 \mathrm{GHz}$. Since their relative intensities were constant from source to source, the lines obviously arose from a single carrier. They were quickly identified by Ken Tucker, P. Thaddeus and Mark Kutner [28] as the $2 \mathrm{fs}$ and $3 \mathrm{hfs}$ components of the $\mathrm{N}=1-0$ rotational transition of $\mathrm{CCH}$. The $\mathrm{CCH}$ radical, which is isoelectronic with $\mathrm{CN}$, has the same fs as the latter, but a simpler hf pattern, the $\mathrm{H}$ atom having a spin of only $1 / 2$ (vs 1 for ${ }^{14} \mathrm{~N}$ ), giving rise to $2 \mathrm{hf}$ sub-levels (vs 3 for the ${ }^{14} \mathrm{~N}$ atom of $\mathrm{CN}$ ). Although it took several more years to observe the microwave spectrum of $\mathrm{CCH}$ in the lab, the astronomical identification was clear as Tucker and co-workers predicted with only 3 constants a pattern that matched the frequencies and relative intensities of the 6 astronomical lines, i.e. 11 parameters. The carrier had to have an odd number of electrons, a ${ }^{2} \Sigma$ ground state and was obeying case $b$ of Hund's coupling cases $(\Lambda=0, \mathbf{J}=\mathbf{N} \times \mathbf{\Sigma})$.

Finally, while searching for cyanodiacetylene (the heavy linear molecule HCCCCCN - see below) in a nearby carbon star envelope named IRC+10216, the author and P. Thaddeus detected at 3-mm two close line doublets, whose center frequencies were exactly in the ratio 9:10. The 9:10 ratio between two successive rotational transitions ( $\mathrm{J}$ or $\mathrm{N}=9-8$ and 10-9) implied a linear molecule of weight similar to that of cyanoacetylene, HCCCN, while the doublets implied an odd number of electrons. The remarkable fact that the doublet separation remained constant from one rotational transition to the next meant a radical obeying Hund's case $b$, like $\mathrm{CCH}$. Only two radicals consisting of elements abundant in a $\mathrm{C}$-rich envelope ( $\mathrm{H}, \mathrm{C}$ and $\mathrm{N}$, since $\mathrm{O}$ is essentially locked into $\mathrm{CO}$ and $\mathrm{SiO}$ ) were fulfilling these criteria: $\mathrm{CCCCH}$ and $\mathrm{CCCN}$, the diacetylenic radical and the cyanoacetylenic radical. With the help of quantum mechanical calculations performed by Sheldon Green, it was possible to differentiate between those two species and to conclude that we were in the presence of CCCN, a radical presumably formed either from photodissociation of the abundant HCCCN molecule, or from the reaction of $\mathrm{CN}$ with acetylene, $\mathrm{HCCH}[14]$.

The identification of $\mathrm{C}_{3} \mathrm{~N}$ without the help of any lab data was first confirmed by the detection of a new series of 3 harmonically related doublets with a constant doublet separation, readily identified with $\mathrm{CCCCH}$ [13] and by the detection of low rotational transitions ( $\mathrm{N}=1-0,2-1$ and 3-2) of both radicals in the dark cloud TMC1 (Guélin et al. 1982). As in the case of $\mathrm{CCH}$, all fine and hf components could be reproduced for each molecules by a set of 4 parameters (see Fig. 5). A year later, $\mathrm{CCH}, \mathrm{C}_{3} \mathrm{~N}$ 


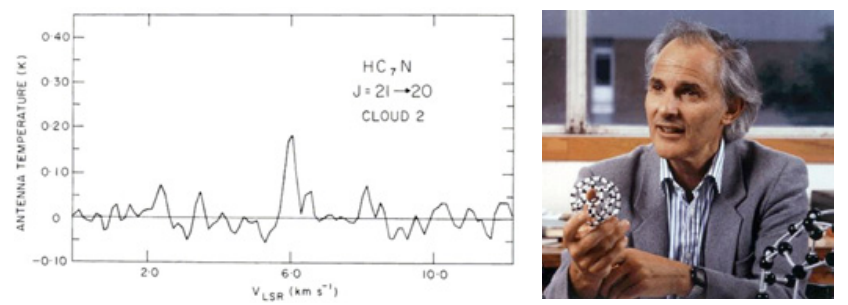

Figure 4. The $\mathrm{J}=21-20$ rotational line of the linear chain molecule $\mathrm{HC}_{7} \mathrm{~N}$ detected in $\mathrm{SgrB} 2$ by Kroto and coworkers in 1977. Harry Kroto, showing a model of the $\mathrm{C}_{60}$ molecule, discovered while trying to synthecize long carbon chain molecules.

and $\mathrm{C}_{4} \mathrm{H}$ could be synthetized in the Harvard microwave lab, bringing an ultimate confirmation of the identifications (Gottlieb et al. 1983).

\section{THE C-CHAIN SAGA}

In 1975, A. Kroto and D. Walton succeeded in forming cyanodiactylene (or cyanobutadyine, $\mathrm{HCCCCCN}$ ) in their spectroscopic laboratory at Sussex University and in measuring its microwave spectrum [18]. A. Kroto was thinking that IS molecules, like dust grains, form in stellar atmospheres and are ejected by stellar winds in the IS medium. The fact that HCN and cyanoacetylene, HCCCN, were both observed in stars and in IS clouds led him to speculate that heavier cyanopolyynes, i.e. long linear chain molecules formed of acetylenic bricks (-CC-) and terminated by $\mathrm{H}$ and $\mathrm{CN}$, may be present in space. Such molecules have a large electric dipole moment and a single rotational energy ladder, two favorable conditions for radio astronomical detection. In addition their large weight ( 75 a.m. for $\mathrm{HC}_{5} \mathrm{~N}$ ) sets the lowest rotational transitions in the $\mathrm{cm}$ or $\mathrm{dm}$ wavelength range, making them observable by the largest radio telescopes. These molecules, composed alternately of single and triple bonds, are physically stable, although they tend to evolve in normal conditions toward ring-like structures. Kroto's idea was brilliantly confirmed by the detection, with the 46-m Algonquin radio telescope, of two rotational lines of $\mathrm{HC}_{5} \mathrm{~N}$ in the giant molecular cloud Sgr B2 and in the dark dust cloud Heiles2/TMC1 (Fig. 4). Kroto and his colleagues from University of Sussex and Herzberg Institute subsequently detected the next 3 species of the series: $\mathrm{HC}_{7} \mathrm{~N}$ and, most remarkably, $\mathrm{HC}_{9} \mathrm{~N}$ and $\mathrm{HC}_{11} \mathrm{~N}$ (147 a.m.u.), for which no spectroscopic data were available. They just noted that the single and triple bond lengths were almost unchanged from $\mathrm{HC}_{5} \mathrm{~N}$ to $\mathrm{HC}_{7} \mathrm{~N}$, making it possible to accurately predict the inertia moments and rotation constants of the longer species. The observation of several rotational transitions confirmed without question the correctness of the identifications even without lab data. The latter arrived only recently.

We have seen in the previous section how $\mathrm{C}_{3} \mathrm{~N}$ and $\mathrm{C}_{4} \mathrm{H}$ were identified without any laboratory information from the fortuitous detection of harmonically related doublets in the spectrum of IRC +10216 while searching for $\mathrm{HC}_{5} \mathrm{~N}$. The envelope $\mathrm{IRC}+10216$, which surrounds the Mira variable $\mathrm{CW}$ Leo, is remarkable as its rich mm-wave spectrum is almost orthogonal with that of Orion $\mathrm{A}(\mathrm{KL})$ : only few percent of the detected mm lines are common to both objects! Contrary to OrionA, IRC+10216 is especially rich in highly unsaturated molecules. Cyanopolyynes are abundant in this source and all those detected, except for $\mathrm{HC}_{11} \mathrm{~N}$, have been observed there. Obviously, the presence of cyano polyynes $\mathrm{H}(\mathrm{CC})_{n} \mathrm{CN}$, such as $\mathrm{HC}_{3} \mathrm{~N}$ and $\mathrm{HC}_{5} \mathrm{~N}$, implied also the presence of non-polar (hence non detectable by radio means) polyacetylenes, $\mathrm{H}(\mathrm{CC})_{n} \mathrm{H}$. The penetration of UV radiation from external stars in the the outer envelope may form, by ablation of one $\mathrm{H}$ atoms, an acetylenic radical $\mathrm{H}(\mathrm{CC})_{n}$, for example, $\mathrm{HCC}$ from acetylene, $\mathrm{HCCH}$. Actually, it is now believed that the long acetylenic radicals form more efficiently from cascade reactions involving $\mathrm{CCH}$ and $\mathrm{HCCH}$. 

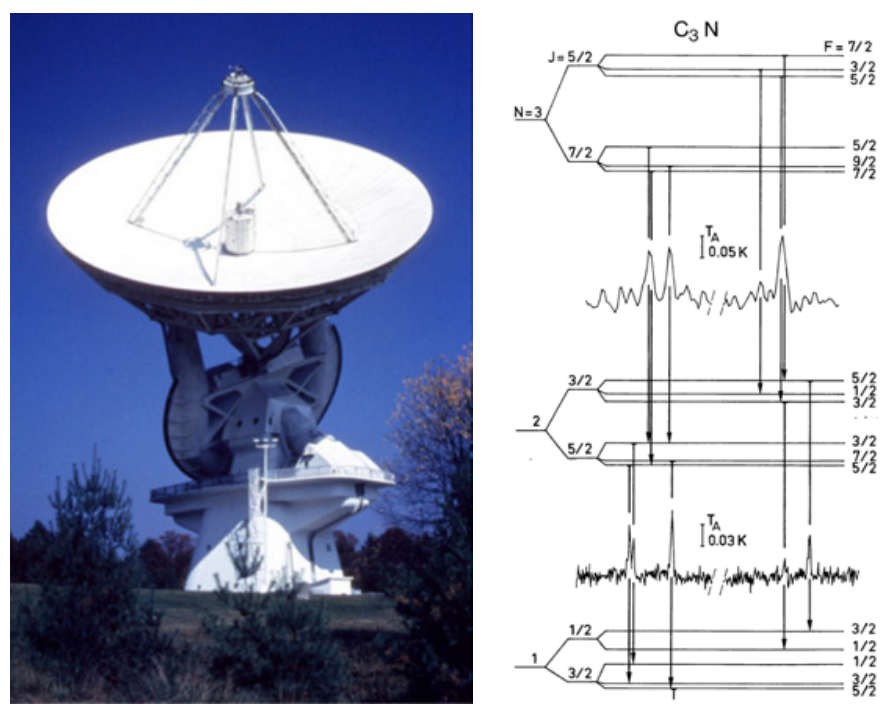

Figure 5. Left: The NRAO 140ft radio telescope, the last large radio telescope with an equatorial mount. The telescope was used in 1969 by Snyder et al. (1969) to discover interstellar formaldehyde and by the author to confirm the identification of the $\mathrm{C}_{3} \mathrm{~N}$ and $\mathrm{C}_{4} \mathrm{H}$ radicals. Right: The $\mathrm{N}=2-1$ and $\mathrm{N}=3-2$ rotational transitions of the $\mathrm{C}_{3} \mathrm{~N}$ radical and the corresponding lines observed in TMC1. Each rotational level is split into two fs sublevels, which are further split into 2 or $3 \mathrm{hf}$ sublevels, giving rise to 5 strong lines. Those, and the corresponding lines of the $\mathrm{N}=3-2$ and $\mathrm{N}=1-0$ transitions can be accurately fitted in frequency and intensity by a single set of 5 parameters: $B, \gamma, b, c$ and $e Q q[12]$.

Acetylenic radicals are linear, like polyacetylenes and cyanopolyynes. Their rotational spectra are thus relatively simple and consist of a series of close doublets with harmonically related frequencies. This simple signature, and the advent in the 1980's of new generation of mm-wave telescopes with larger collecting areas, better receivers and wider back-ends, the 20-m Onsala telescope, the Nobeyama 45-m telescope and, mostly, the IRAM 30-m telescope, boosted the sensitivity of molecular searches in small-size sources such as Orion (KL), TMC 1, and IRC+10216, making it possible to perform blind line surveys. The observation of $\mathrm{C}_{3} \mathrm{~N}$ and $\mathrm{C}_{4} \mathrm{H}$ in IRC+10216 and TMC 1 , as well as that of long cyanopolyynes, showed that longer acetylenic chains may also be detected. Spectral surveys were carried out in these sources which led to the discovery of several series of harmonically related line doublets (with integer or half-integer rotational quantum numbers) which, on the basis of ab-initio quantum mechanical calculations of their geometrical structures and on the behaviour of the doublet splittings with increasing $\mathrm{J}$ number, were identified with $\mathrm{C}_{3} \mathrm{H}, \mathrm{C}_{5} \mathrm{H}, \mathrm{C}_{6} \mathrm{H}, \mathrm{C}_{8} \mathrm{H}$ and a mysterious linear radical, recognized seven years later by Kentaro Kawaguchi and co-workers as the metal-bearing radical MgNC [16], thanks to hard spectroscopic lab work.

\section{METAL-BEARING SPECIES AND STILL MORE RADICALS}

MgNC was not the first metal-bearing molecule identified in the gas of the IRC+10216 circumstellar envelope (CSE). Prior to it, Jose Cernicharo and the author (Cernicharo \& Guélin 1986) assigned four series of harmonically related lines from our 30-m telescope mm-wave spectral survey of IRC+10216 to rotational transitions of the closed-shell molecules $\mathrm{NaCl}, \mathrm{AlCl}, \mathrm{KCl}$ and $\mathrm{AlF}$. Those species, which contain refractory elements, form in the hot $(\simeq 2300 \mathrm{~K})$ atmosphere of the star, from which they are expelled; they condense onto dust grains as the gas expands and cools down, or are quickly destroyed by ion-molecule reactions. Other closed-shell molecules containing refractory elements such as $\mathrm{Na}, \mathrm{K}$, 


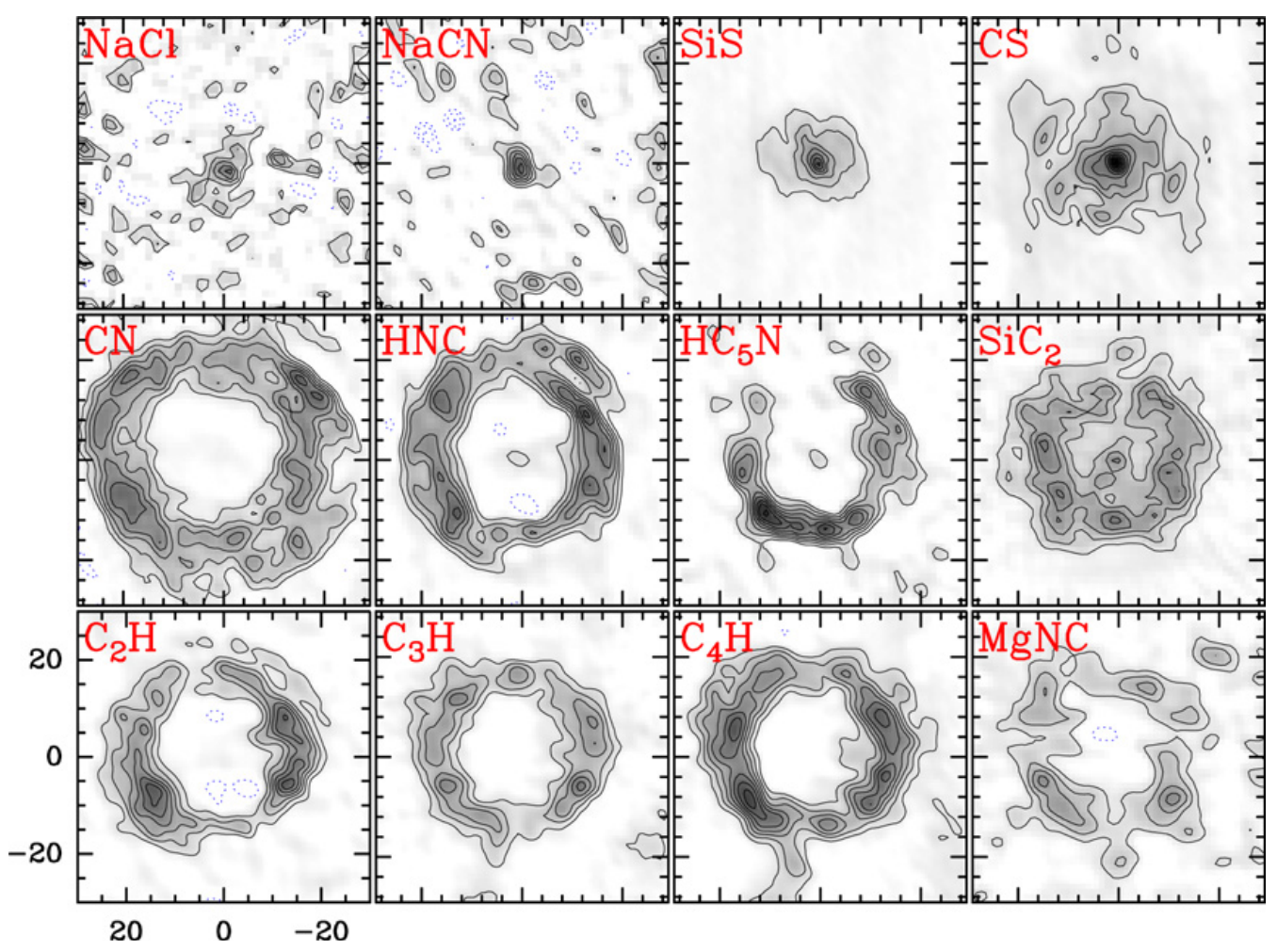

Figure 6. 3-mm rotational line emission from different molecular species observed in the circumstellar envelope IRC+10216 with the Plateau de Bure Interfrometer at a resolution of a few arcsec. Abscissa and ordinate represent offsets in arcsec from the position of the central star, CW Leo. The maps show the emission in the expanding envelope at the velocity of the star: an expanding gaseous shell appears in the maps as a ring ( $2^{\prime \prime}$ corresponds to $\simeq 100 \mathrm{yr}$ ). Note that molecules containing refractory elements, such as $\mathrm{NaCl}, \mathrm{NaCN}$ and $\mathrm{SiS}$ (but not $\mathrm{MgNC}$ ), which are expelled from the stellar atmosphere, are observed only close to the star in the gas phase. Conversely, radicals and carbon chain molecules are formed in the outer envelope and appear after $800 \mathrm{yr}$ or so - see sec. 8 below. Adapted from Guélin et al. (1995).

$\mathrm{Ti}$ and $\mathrm{P}$ are known to exist in the atmospheres and/or inner envelopes of $\mathrm{C}$ - and $\mathrm{O}$-rich stars and several Si-bearing molecules are observed in the inner and outer envelope of IRC+10216. What is remarkable with the MgNC radical, is that it is not observed close to the star, but only in a narrow shell of the cold outer envelope, where $T_{k} \leq 30 \mathrm{~K}$ (Guélin et al. 1993). Obviously, it must form there. High angular resolution observations of $\mathrm{C}$-chain molecules and radicals show similar shell-like distribution with the same radius (Fig. 6).

Thanks to progress in sensitivity due to new-generation receivers, more refractory element-bearing molecules and radicals where identified in CSEs (see Turner 1995 for a review). This is the case in particular for the $\mathrm{MgCN}, \mathrm{AlNC}, \mathrm{CP}, \mathrm{SiC}, \mathrm{SiCN}, \mathrm{SiNC}$ radicals, which have all been observed in IRC+10216 and which, judging from their line shapes, seem all constrained to the same shell as $\mathrm{MgNC}$. Other gas-phase metal-bearing molecules identified in IRC+10216 are NaCN, KCN and FeNC. We come back below on how this may be interpreted in terms of chemistry. IRC+10216 and its central star CW Leo are C-rich and most of the oxygen in the envelope is locked, as we have seen, into CO and $\mathrm{SiO}$. Weak emission from $\mathrm{H}_{2} \mathrm{O}, \mathrm{H}_{2} \mathrm{CO}$ and $\mathrm{C}_{3} \mathrm{O}$ is nevertheless observed. Remarkably, high energy $\left(E / k \geq 100 \mathrm{~K}\right.$ ) lines of $\mathrm{H}_{2} \mathrm{O}$ have recently been detected with HIFI/Herschel (Decin et al. 2011), which show that water forms very close to the star. 
Oxygen is not locked into $\mathrm{CO}$ in less evolved stars, like VY-Canis Majoris, where $[\mathrm{C}] /[\mathrm{O}]<1$. There, among some 20 molecular species, 8 oxygen-bearing molecules are observed in addition to $\mathrm{CO}$ and $\mathrm{SiO}: \mathrm{OH}, \mathrm{H}_{2} \mathrm{O}, \mathrm{HCO}^{+}, \mathrm{AlOH}, \mathrm{AlO}, \mathrm{PO}, \mathrm{SO}$ and $\mathrm{SO}_{2}$. Moreover, the signature silicate-containing dust is detected in the infrared.

\section{NON POLAR SPECIES}

Fully symmetric molecules, such as the linear $\mathrm{C}_{n}$ chains and polyacetylenes $\left(\mathrm{HC}_{2 n} \mathrm{H}\right)$, have no permanent electric dipole moments, hence no strong rotational transitions within a given vibrational state. They hardly can be observed at millimeter wavelengths, but do have strong electronic transitions in the UV and ro-vibrational transitions in the near- or mid-infrared. These transitions involve upper levels with energies of several hundreds to several thousands of $\mathrm{K}$ and are seldom excited in the interor circumstellar gas; they may however be observed in absorption against stars. This is the case of $\mathrm{H}_{2}$, as we have seen, but also of $\mathrm{N}_{2}, \mathrm{CH}_{4}$ and $\mathrm{H}_{3}^{+}$, which have been observed in the UV or IR toward bright stars.

Similarly, $\mathrm{C}_{2}, \mathrm{C}_{3}, \mathrm{C}_{4}$ and $\mathrm{C}_{5}$ have all been detected through their IR and FIR bands against the very bright inner envelope of IRC+10216. Same thing for acetylene $(\mathrm{HCCH})$, ethylene $\left(\mathrm{H}_{2} \mathrm{C}_{2} \mathrm{H}_{2}\right)$ and silane $\left(\mathrm{SiH}_{4}\right)$. Di-acetylene $\left(\mathrm{HC}_{4} \mathrm{H}\right)$ and tri-acetylene $\left(\mathrm{HC}_{6} \mathrm{H}\right)$ have been identified in another $\mathrm{C}$-rich star envelope, CRL 618, with the Infrared Space Observatory (ISO), together with benzene $\left(\mathrm{C}_{6} \mathrm{H}_{6}-\right.$ Cernicharo et al. 2001).

The quest for molecular oxygen, another homonuclear species, has been a particularly long one. Firstly, $\mathrm{O}_{2}$ from the terrestrial atmosphere absorbs the radiation from astronomical sources. One thus have to go to space for its astronomical observation. Secondly, $\mathrm{O}_{2}$ has no permanent electric dipole moment. In its ground electronic state, $\mathrm{O}_{2}$ has however the remarkable property that its two outer electrons are paired with parallel spins $\left({ }^{3} \Sigma\right)$. This gives rise to magnetic dipole transitions that, althrough intrinsically $\sim 10^{2-3}$ times weaker than typical electric dipole transitions, are nevertheless observable. The lowest such transition is the $(J, N)=1,1 \leftarrow 0,1$ transition, which has a frequency of $118.75 \mathrm{GHz}(\lambda=2.6 \mathrm{~mm})$. This line has been tentatively detected in a dark molecular cloud with the Odin satellite [20] and very low upper limits have been set to its intensity in other sources. Despite the large cosmic abundance of oxygen, there is surprisingly little molecular oxygen in interstellar clouds, a result confirmed by a new deep survey carried out with the HERSCHEL satellite.

\section{RINGS, BENZENE, PAHS AND FULLERENES}

Another mystery of astrochemistry is the scarcity of molecular rings, as opposed to the large number of linear C-chains observed in circumstellar envelopes (such as IRC+10216 and CRL618), in dark cold molecular clouds (such as TMC 1) and in warm giant molecular clouds (such as Sgr B2). Only 5 rings, $\mathrm{SiC}_{2}, \mathrm{c}-\mathrm{C}_{3} \mathrm{H}, \mathrm{C}_{3} \mathrm{H}_{2}, \mathrm{c}-\mathrm{C}_{2} \mathrm{H}_{4} \mathrm{O}, \mathrm{c}-\mathrm{C}_{3} \mathrm{H}_{2} \mathrm{O}$ have been unambiguously identified through several rotational transitions. Benzene, $\mathrm{C}_{6} \mathrm{H}_{6}$, is detected in only one source, CRL 618, and only through its strongest IR band, the $v_{4}$ Q-branch at $14.8 \mu \mathrm{m}$. Why are we not observing more benzenic rings? Unsuccessful searches have been made for benzene in other sources, as well as for toluene (benzene with on $\mathrm{H}$ atom substituted with $\left.\mathrm{CH}_{3}\right)$, phenol $(\mathrm{H}$ substituted with $\mathrm{OH})$ and pyridine $\left(\mathrm{C}_{5} \mathrm{H}_{5} \mathrm{~N}\right)$, three polar molecules with intrinsically strong millimetric wave transitions.

Molecules based on two or more benzenic rings are called Polycyclic Aromatic (PA) molecules or PA hydrocarbons (PAH) when they do not contain atoms other than carbon or hydrogen. The smallest $\mathrm{PAH}$, called naphthalene, consists of two benzenic rings; it is is non-polar like most small PAHs, hence has no microwave rotational transitions.

PAHs, even highly symmetric ones, do have strong infrared ro-vibrational transitions that correspond to the stretching and bending of their many $\mathrm{C}-\mathrm{C}-\mathrm{H}$ segments. Because the stretching/bending frequencies of each segment depend on its surroundings, the transitions pile up into broad emission bands. Those 
have wavelengths close to the "unidentified diffuse IR" bands (UIR), at 3.3, 6.2, 7.7, 8.6 and 11.3 micron, that are observed in Reflection- and Planetary Nebulae. In 1984, Leger and Puget proposed to assign those IUR bands to PAH molecules with less than 50 or so C atoms [19] (see also Allamandola et al. [7]). Other possible carriers of the UIR bands, first pointed out by Duley and Williams (1981), are very small grains formed of hydrogenated amorphous carbon (HAC). Anthracite grains have also been proposed.

Much astronomical, laboratory and theoretical work has gone since the 80's in trying to confirm the PAH hypothesis. Yet, the question of the origine of IUR bands remains unsettled: despite striking matches, no single PAH or group of PAHs, either neutral, or ionized, is found to accurately fit those bands. If true, the PAH hypothesis implies that 5 to $10 \%$ of interstellar carbon is locked into large cyclic molecules, that is more than in CO. The reader is referred to Tielens' (2011) and Thaddeus' reviews (2006) [26] for conflicting views on the PAH hypothesis.

UIR bands, the so-called "PAH bands", are not the only unidentified bands observed in interstellar space. The oldest and most studied such bands are the diffuse interstellar bands (DIBs) that spread all across the visible spectrum. Those are seen in absorption against bright stars; their number exceeds 400; their width is typically larger than $10 \mathrm{~A}$, although narrow substructures $1 \mathrm{~A}$-wide are observed with high spectral resolution. The first DIBs were observed by Mary Lea Heger as early as in 1922 and it was soon recognized that they arise in the interstellar medium. Much broader than usual interstellar lines and showing fairly narrow substructures, their carriers must be molecules. Contrary to UIR bands, the intensities of the different DIBs hardly correlate from source to source. Thus, they cannot be ascribed to a single molecular species, but must come from several families of molecules.

Almost ninety years after their discovery, the nature of the DIBs, like that of UIR bands, is still a mystery, although it is agreed that they should arise from large organic molecules. Long C-chains (Douglas 1977), PAHs and spherical C-atom structures named fullerenes (Kroto 1990) have been considered. The name of fullerenes stems from their similarity with the architectural structures of Buckminster Fuller that resembles a football and consists of a network of hexagons and pentagons. Whereas adjacent $\mathrm{C}$-atom hexagons make up planar carbon lattices (like in PAHs or graphite), the inclusion of pentagons shapes up the structure into a sphere. Such structures may be very strong. The most stable fullerenes are $\mathrm{C}_{60}$ and $\mathrm{C}_{70}$, which have a high degree of symmetry. They were discovered in the laboratory by Harry Kroto, while trying to synthesize long carbon chains during his quest for large interstellar cyanopolyynes and polyacetylenes. It is remarkable that an astronomically-oriented research led to the discovery of a new cristalline form of carbon, besides planar lattices and tetragonal pyramids, nanospheres, which have very interesting properties as concerns mechanical strength and conductivity. The discovery in 1984 of $\mathrm{C}_{60}$, "Buckminsterfullerene", by Kroto, Smalley, Curl and collaborators (Fig. 7) and, more generally, that of fullerenes, which have interesting practical applications, led the 3 scientists to share the Nobel Price of Chemistry 12 years later - a remarkably short interval of time for a basic research topic!

Recently, Jan Cami and collaborators tentatively identified 7 well resolved UIR bands, observed by the space telescope SPITZER in the mid-IR spectrum of a Planetary Nebula, with 3 bands of $\mathrm{C}_{60}$ and 4 bands of $\mathrm{C}_{70}$ (Fig. 7). This identification is now strengthen by the observation of the very same $\mathrm{C}_{60}$ bands, together with MIR bands attributed to PAHs, in a number of Planetary Nebulae. $\mathrm{C}_{60}$ (and PAHs?) would form by photodissociation of HAC grains in the strong UV radiation of the central star.

For the sake of completeness, let us quote the work of Maier and collaborators (2011), who proposed the linear allenic chain $\mathrm{H} 2 \mathrm{CCC}$ as carrier of a fairly narrow DIB, a somewhat controversial identification.

\section{THE PREBIOTIC TRAIL}

Besides fullerenes, a number of fairly complex organic molecules (with up to 13 atoms) have been identified in interstellar space. Some are biomolecular precursors which were end products of the stark 


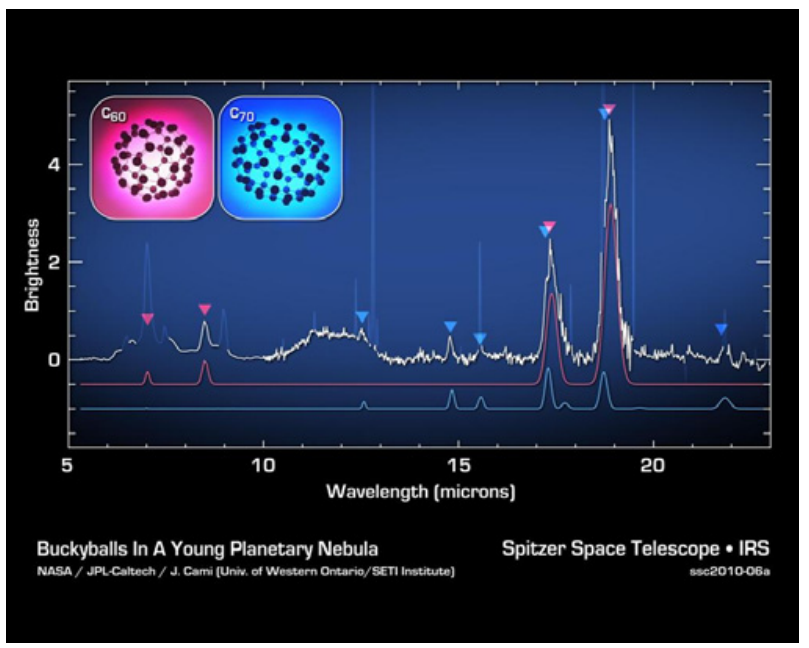

Figure 7. Diffuse interstellar bands detected in the mid IR by the SPITZER satellite toward a young Planetary Nebula. The lines were recently identified by J. Cami and co-workers as vibrational modes of the spherical C structures $\mathrm{C}_{60}$ and $\mathrm{C}_{70}$, discovered in the lab by $\mathrm{H}$. Kroto and co-workers and proposed by him as possible carriers of the DIBs.
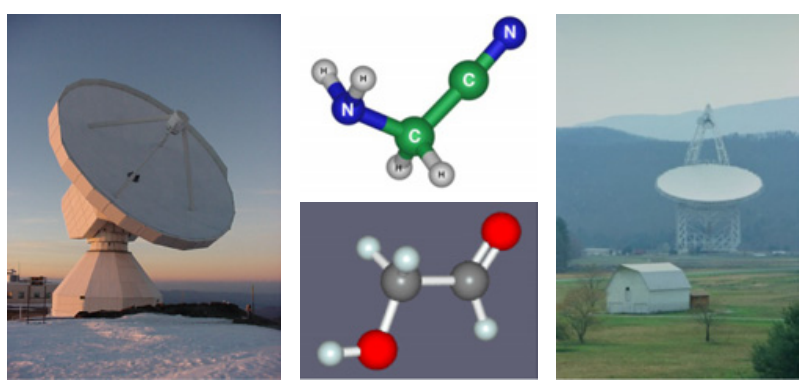

Figure 8. The IRAM 30-m Pico Veleta telescope (left) and the NRAO 100-m Green Bank telescope (right), which have been used to identify a number of complex interstellar molecules. Amino acetonitrile (top) and glycolaldehyde (bottom); the latter is an isomer of acetic acid and methylformate. Those 4 organic molecules have been identified in the Galactic Center molecular cloud Sgr B2-N.

discharge Miller-Urey experiment. We have noted the early discovery of interstellar formaldehyde which is ubiquitous in IS clouds. Since then, astronomers identified methanol, ethanol, vinyl alcohol, acetone $\left(\mathrm{CH}_{3}\right)_{2} \mathrm{CO}$, a key organic species, several aldehydes, including the sugar glycolaldehyde $\left(\mathrm{CH}_{2} \mathrm{OHCHO}\right)$, and two molecules with peptide bonds, $-\mathrm{C}(=\mathrm{O}) \mathrm{NH}-\mathrm{a}$ milestone on the path to polypeptides and proteines: formamide $\left(\mathrm{NH}_{2} \mathrm{CHO}\right)$ and acetamide $\left(\mathrm{CH}_{3} \mathrm{CONH}_{2}\right)$.

The next milestone would be to find amino acids in interstellar space. The simplest amino acid is glycine, $\mathrm{NH}_{2} \mathrm{CH}_{2} \mathrm{COOH}$, the microwave rotational spectrum of which has been characterized some 30 years ago. So far, and despite many deep searches (and a reported detection of glycine, invalidated by more sensitive observations) neither glycine, nor any other amino acid have been found in an interstellar source. Such molecules are however observed in meteorites. Amino acetonitrile, $\mathrm{NH}_{2} \mathrm{CH}_{2} \mathrm{CN}$, a possible precursor of glycine, has nevertheless been observed in SgrB2-N.

Very recently, Hsin-Lun Kuo and collaborators have reported at the 2010 Midwest astrochemistry meeting (mwac.meet) the detection in SgrB2-N of eight weak lines they tentatively ascribe to urea, $\left(\mathrm{NH}_{2}\right)_{2} \mathrm{CO}$. 


\section{BREATH-CUTTING INTERSTELLAR ANIONS}

We have seen that three cations, $\mathrm{CH}^{+}, \mathrm{HCO}^{+}$and $\mathrm{N}_{2} \mathrm{H}^{+}$were among the first identified interstellar molecules. From the start, ion-molecule chemistry models predicted that molecular cations must be abundant in the dark interstellar clouds and must play an important role in the formation of polyatomic molecules. The identifications of $\mathrm{HCO}^{+}$and $\mathrm{N}_{2} \mathrm{H}^{+}$soon confirmed the pertinence of ion-molecule models, as subsequently did the detection of $\mathrm{H}_{3}^{+}$and of many cations that are protonated forms of some of the most abundant atoms or closed shell molecules: $\mathrm{HCNH}^{+}, \mathrm{HCS}^{+}, \mathrm{HOCO}^{+}, \mathrm{H}_{2} \mathrm{O}^{+}, \mathrm{H}_{3} \mathrm{O}^{+}$, $\mathrm{H}_{2} \mathrm{COH}^{+}, \mathrm{H}_{2} \mathrm{Cl}^{+}, \mathrm{SH}^{+}$.

The detection of interstellar anions in dense clouds and circumstellar envelopes came more as a surprise. Although, the formation of $\mathrm{C}$-chain anions by radiative attachment of an electron to long $\mathrm{C}$ chain radicals was theorized long ago (Herbst 1981), it draw little attention because those radicals were not abundant and because the geometry and spectral signatures of anions were unknown. It is only a few years ago, following the idea that a series of harmonically related lines, detected in IRC +10216 by Kawaguchi and colleagues, presumably arose form a new linear, closed-shell molecule of weight similar to $\mathrm{C}_{6} \mathrm{H}$, and could come from $\mathrm{C}_{6} \mathrm{H}^{-}$, that Harvard spectroscopists succeeded in synthetizing this anion in the laboratory and measuring its mm-wave spectrum.

The characterization of the rotational spectra of the $\mathrm{C}$-chain anion $\mathrm{C}_{6} \mathrm{H}^{-}$(McCarthy et al. 2006), followed by those of $\mathrm{C}_{8} \mathrm{H}^{-}, \mathrm{C}_{4} \mathrm{H}^{-}, \mathrm{CN}^{-}$and $\mathrm{C}_{3} \mathrm{~N}^{-}$, came as a breakthrough. All those species were subsequently identified in the mm spectrum of IRC+10216 (Cernicharo et al. 2008a; Agundez et al. 2010), as was a sixth anion, so far unknown in the laboratory, $\mathrm{C}_{5} \mathrm{~N}^{-}$(Cernicharo et al. 2008b).

As we have seen, negative ions, are believed to form by radiative attachment of an electron to a neutral molecule. It was pointed out that a high electron affinity and a large number of vibrational states of low energy greatly increase the sticking coefficient of electrons, so that large, negatively charged carbon chains of the form $\mathrm{C}_{n} \mathrm{H}^{-}$may be abundant. In particular, Millar et al. (2000) predicted in some sources an abundance of $\mathrm{C}_{8} \mathrm{H}^{-}$as large as $1 / 4$ of that of its neutral counterpart, $\mathrm{C}_{8} \mathrm{H}$.

The detection of $\mathrm{C}_{2 n} \mathrm{H}^{-}(n=2,3,4)$ in IRC +10216 , in cold dark clouds and in star-forming cores, and of $\mathrm{C}_{2 n+1} \mathrm{~N}^{-}(n=0,1,2)$ in IRC+10216 demonstrates that anions are indeed abundant in the interstellar gas - as a matter of fact much more abundant than cations, relative to their neutral counterparts (e.g. $\mathrm{HC}_{3} \mathrm{NH}^{+}$relative to $\mathrm{HC}_{3} \mathrm{~N}$ ).

The abundances of $\mathrm{C}_{2 n} \mathrm{H}^{-}$and $\mathrm{C}_{2 n+1} \mathrm{~N}^{-}$depend on the rate coefficient of electron radiative attachment on the neutral parent radicals, $k e_{\text {rad }}$, a critical parameter of chemical models that has never been measured in the laboratory. It is only inferred form ternary reaction rate measurements and/or from simple statistical calculations (see Herbst 1981; Terzieva \& Herbst 2000). To simplify, the longer the radical, the larger are $k e_{\text {rad }}$ and the anion-to-neutral ratio.

The uncertainties on the attachment rates are however large. For example, whereas the observed abundances of $\mathrm{C}_{8} \mathrm{H}^{-}$and $\mathrm{C}_{6} \mathrm{H}^{-}$are close to those predicted, i.e. as large 1/10-2/10 of the abundances of the neutral parent species $\mathrm{C}_{8} \mathrm{H}$ and $\mathrm{C}_{6} \mathrm{H}$, the observed abundance of $\mathrm{C}_{4} \mathrm{H}^{-}$relative to $\mathrm{C}_{4} \mathrm{H}$ is a factor $10^{2}$ too low and the abundance of $\mathrm{CN}^{-}$, several orders of magnitude too large! Obviously, we don't know how to estimate $k e_{\text {rad }}$ for the shorter chains and additional formation/destruction routes not considered so far may be active. We show in the next section how high angular resolution observations may help in evaluating reaction rates.

\section{TIME-DEPENDENT CHEMISTRY}

The expanding C-rich circumstellar envelope IRC+10216 has an almost spherical shape and a nearly uniform expansion velocity $\left(14.5 \mathrm{kms}^{-1}\right)$. These properties makes it easy to calculate the age of a shell of gas as a function of its radius. The radius of an expanding shell is best measured at velocities close to the star velocity, $v *=-26.5 \mathrm{kms}^{-1}$, where the shell emission takes the form of a ring in the plane of the sky. The gas temperature and density profiles are relatively well known in the outer envelope, so that IRC+10216 is an ideal "laboratory" for testing time-dependent chemistry. 


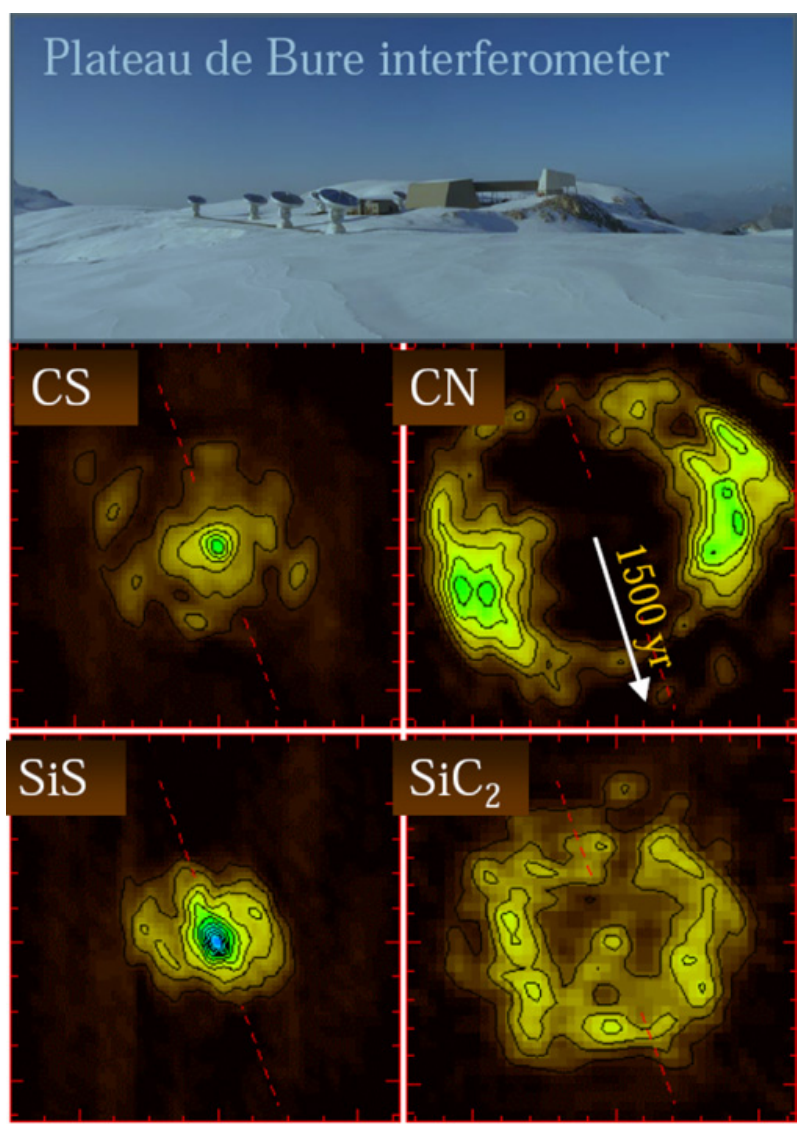

Figure 9. Emission in the 3-mm lines of $\mathrm{SiS}, \mathrm{SiC}_{2}, \mathrm{CS}$ and $\mathrm{CN}$ at velocities close to the star velocity, observed with the IRAM Plateau de Bure interferometer (Lucas and Guélin, 1993).

We have started to investigate the formation of the C-chain anions and of their neutral parent radicals by mapping with the Plateau de Bure interferometer (PdBI) the emission of their mm-wave lines. The spatial distributions of $\mathrm{C}_{2} \mathrm{H}, \mathrm{C}_{4} \mathrm{H}$ and $\mathrm{C}_{6} \mathrm{H}$ are almost identical; these species are observed inside two fairly narrow shells of radii $\simeq 15^{\prime \prime}$ and $30^{\prime \prime}$ (800 and $1600 \mathrm{yr}$ ). That $\mathrm{C}_{2} \mathrm{H}$, contrary to $\mathrm{CO}, \mathrm{SiO}, \mathrm{HCN}$ and $\mathrm{HCCH}$, appears only in the outer envelope is easily understood if it results from the photodissociation of HCCH by interstellar UV and is destroyed by neutral-neutral reactions and further photodissociation. What is more surprising is that $\mathrm{C}_{4} \mathrm{H}$ and $\mathrm{C}_{6} \mathrm{H}$, which are believed to form slowly from $\mathrm{CCH}$, appear at the same radius. Even more surprising, the anions $\mathrm{C}_{6} \mathrm{H}^{-}$and $\mathrm{C}_{4} \mathrm{H}^{-}$, which seem also confined into narrow shells are observed at a smaller radius, i.e. earlier, than their parent species $\mathrm{C}_{6} \mathrm{H}$ and $\mathrm{C}_{4} \mathrm{H}$. Whereas the similarity of the spatial distributions of $\mathrm{C}_{2} \mathrm{H}, \mathrm{C}_{4} \mathrm{H}$ and $\mathrm{C}_{6} \mathrm{H}$ (as well as many other radicals and molecules, such as $\mathrm{MgNc}$ and the $\mathrm{C}$-chains $\mathrm{C}_{3} \mathrm{~N}, \mathrm{HC}_{5} \mathrm{~N}$ and $\mathrm{HC}_{7} \mathrm{~N}$ ) may be explained by the presence of narrow and very dense gas shells, resulting from episodic mass losses, that speed up chemistry and collisionally excite those polar molecules, the appearance of the highly polar anions $\mathrm{C}_{6} \mathrm{H}^{-}$and $\mathrm{C}_{4} \mathrm{H}^{-}$ ahead of (i.e. before) those dense shells does not fit to the picture.

\section{TOWARDS THE TOWER OF BABEL}

The quest for interstellar molecules could not have been as successful without the formidable development of radio telescopes and, more particularly, since the late 1960's, of mm/sub-mm telescopes. 


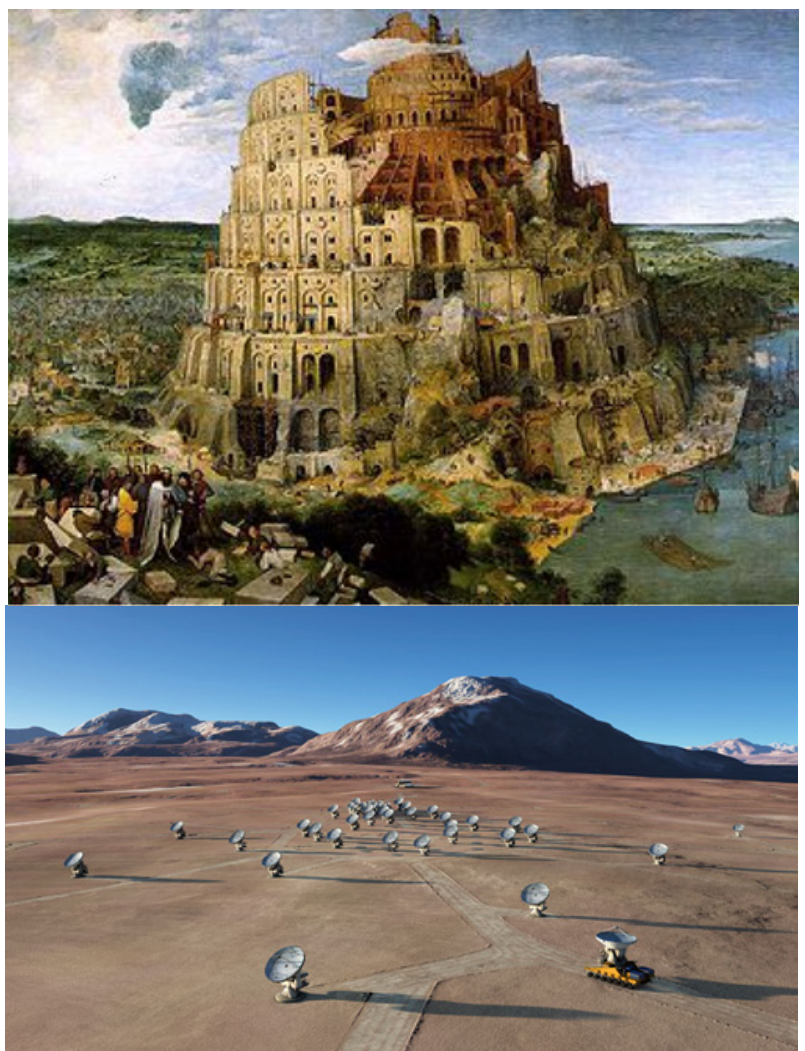

Figure 10. Peter Bruegel's view of the Tower of Babel. ALMA, as it will look like after completion, in 2014.

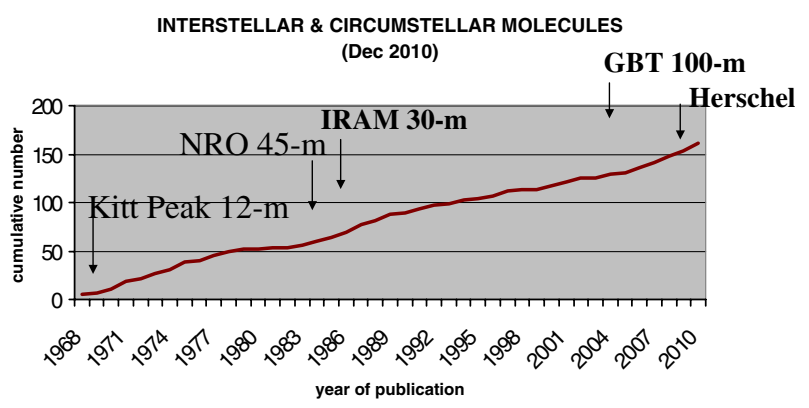

Figure 11. Interstellar and Circumstellar molecules (not counting the different isotopomeres) as reported before Dec. 2010 (see The Astrochymist).

Fig. 11 shows, as a function of time, the number of molecular species identified in interstellar sources (interstellar clouds and circumstellar envelopes) since 1968. The dates of completion of new radio telescopes are indicated by black arrows. Although the number of identified species has steadily increased by $\simeq 30$ molecules per decade, the rate of discoveries temporarily increases after major instruments are brought in operation (or that new generation, more sensitive receivers are installed). This was particularly the cases for the NRAO Kitt Peak 36-foot telescope in the 1970's, the Nobeyama 45-m telescope in the 1980's, the IRAM 30-m telescope in 1986, 1996 and 2008, the Infrared Space Observatory in 1996, the NRAO Green Bank telescope in 2005. The last increase, since 2009, is 
Table 1. Interstellar and circumstellar molecular species identified as of Sep 2011 (adapted from the Cologne Molecular Data Basis; http://www.astro.uni-koeln.de). Molecules with e and v superscripts are observed only through electronic and vibrational transitions at optical and IR wavelengths. Cyclic molecules are headed by $\mathrm{c}^{-}$.

\begin{tabular}{|c|c|c|c|c|c|c|c|c|c|}
\hline 2 atoms & 3 atoms & 4 atoms & 5 atoms & 6 atoms & 7 atoms & 8 atoms & 9 atoms & 10 atoms & $\geq 11$ atoms \\
\hline $\mathrm{H}_{2}$ & $\mathrm{C}_{3}^{v}$ & $c-C_{3} \mathrm{H}$ & $\mathrm{C}_{5}^{v}$ & $\mathrm{C}_{5} \mathrm{H}$ & $\mathrm{C}_{6} \mathrm{H}$ & $\mathrm{CH}_{3} \mathrm{C}_{3} \mathrm{~N}$ & $\mathrm{CH}_{3} \mathrm{C}_{4} \mathrm{H}$ & $\mathrm{CH}_{3} \mathrm{C}_{5} \mathrm{~N}$ & $\mathrm{HC}_{9} \mathrm{~N}$ \\
\hline $\mathrm{AlF}$ & $\mathrm{C}_{2} \mathrm{H}$ & $\mathrm{C}_{3} \mathrm{H}$ & $\mathrm{C}_{4} \mathrm{H}$ & $\mathrm{H}_{2} \mathrm{C}_{4}$ & $\mathrm{CH}_{2} \mathrm{CHCN}$ & $\mathrm{HC}(\mathrm{O}) \mathrm{OCH}_{3}$ & $\mathrm{CH}_{3} \mathrm{CH}_{2} \mathrm{CN}$ & $\left(\mathrm{CH}_{3}\right)_{2} \mathrm{CO}$ & $\mathrm{HC}_{11} \mathrm{~N}$ \\
\hline $\mathrm{AlCl}$ & $\mathrm{C}_{2} \mathrm{O}$ & $\mathrm{C}_{3} \mathrm{~N}$ & $\mathrm{C}_{4} \mathrm{Si}$ & $\mathrm{C}_{2} \mathrm{H}_{4}^{v}$ & $\mathrm{CH}_{3} \mathrm{CCH}$ & $\mathrm{CH}_{3} \mathrm{C}(\mathrm{O}) \mathrm{OH}$ & $\left(\mathrm{CH}_{3}\right)_{2} \mathrm{O}$ & $\left(\mathrm{CH}_{3} \mathrm{OH}\right)_{2}$ & $\mathrm{C}_{2} \mathrm{H}_{5} \mathrm{OCHO}$ \\
\hline $\mathrm{C}_{2}^{e}$ & $\mathrm{C}_{2} \mathrm{~S}$ & $\mathrm{C}_{3} \mathrm{O}$ & $\mathrm{C}_{3} \mathrm{H}_{2}$ & $\mathrm{CH}_{3} \mathrm{CN}$ & $\mathrm{HC}_{5} \mathrm{~N}$ & $\mathrm{C}_{7} \mathrm{H}$ & $\mathrm{CH}_{3} \mathrm{CH}_{2} \mathrm{OH}$ & $\mathrm{CH}_{3} \mathrm{CH}_{2} \mathrm{CHO}$ & $\mathrm{C}_{6} \mathrm{H}_{6}^{v}$ \\
\hline $\mathrm{CH}$ & $\mathrm{CH}_{2}$ & $\mathrm{C}_{3} \mathrm{~S}$ & $c-C_{3} \mathrm{H}_{2}$ & $\mathrm{CH}_{3} \mathrm{NC}$ & $\mathrm{CH}_{3} \mathrm{CHO}$ & $\mathrm{H}_{2} \mathrm{C}_{6}$ & $\mathrm{HC}_{7} \mathrm{~N}$ & & $\mathrm{C}_{2} \mathrm{H}_{5} \mathrm{OCH}_{3}(?)$ \\
\hline $\mathrm{CH}^{+}$ & $\mathrm{HCN}$ & $\mathrm{C}_{2} \mathrm{H}_{2}^{v}$ & $\mathrm{H}_{2} \mathrm{CCN}$ & $\mathrm{CH}_{3} \mathrm{OH}$ & $\mathrm{CH}_{2} \mathrm{NH}_{2}$ & $\mathrm{CH}_{2} \mathrm{OHCHO}$ & $\mathrm{C}_{8} \mathrm{H}$ & & $\mathrm{C}_{60}$ \\
\hline $\mathrm{CN}$ & $\mathrm{HCO}$ & $\mathrm{NH}_{3}$ & $\mathrm{CH}_{4}^{v}$ & $\mathrm{CH}_{3} \mathrm{SH}$ & $c-C_{2} \mathrm{H}_{4} \mathrm{O}$ & $\mathrm{HC}_{6} \mathrm{H}^{v}$ & $\mathrm{CH}_{3} \mathrm{C}(\mathrm{O}) \mathrm{NH}_{2}$ & & $\mathrm{C}_{70}^{v}$ \\
\hline $\mathrm{CO}$ & $\mathrm{HCO}^{+}$ & $\mathrm{HCCN}$ & $\mathrm{HC}_{3} \mathrm{~N}$ & $\mathrm{HC}_{3} \mathrm{NH}^{+}$ & $\mathrm{H}_{2} \mathrm{CCHOH}$ & $\mathrm{CH}_{2} \mathrm{CHCHO}(?)$ & $\mathrm{C}_{8} \mathrm{H}^{-}$ & & $c-C_{3} \mathrm{H}_{7} \mathrm{CN}$ \\
\hline $\mathrm{CO}^{+}$ & $\mathrm{HCS}^{+}$ & $\mathrm{HCNH}^{+}$ & $\mathrm{HC}_{2} \mathrm{NC}$ & $\mathrm{HC}_{2} \mathrm{CHO}$ & $\mathrm{C}_{6} \mathrm{H}^{-}$ & $\mathrm{CH}_{2} \mathrm{CCHCN}$ & $\mathrm{C}_{3} \mathrm{H}_{6}$ & & $\mathrm{CH}_{3} \mathrm{C}_{6} \mathrm{H}$ \\
\hline $\mathrm{CP}$ & $\mathrm{HOC}^{+}$ & HNCO & $\mathrm{HCOOH}$ & $\mathrm{NH}_{2} \mathrm{CHO}$ & & $\mathrm{NH}_{2} \mathrm{CH}_{2} \mathrm{CN}$ & & & \\
\hline $\mathrm{SiC}$ & $\mathrm{H}_{2} \mathrm{O}$ & HNCS & $\mathrm{H}_{2} \mathrm{CNH}$ & $\mathrm{C}_{5} \mathrm{~N}$ & & & & & \\
\hline $\mathrm{HCl}$ & $\mathrm{H}_{2} \mathrm{~S}$ & $\mathrm{HOCO}^{+}$ & $\mathrm{H}_{2} \mathrm{C}_{2} \mathrm{O}$ & $\mathrm{HC}_{4} H^{v}$ & & & & & \\
\hline $\mathrm{KCl}$ & HNC & $\mathrm{H}_{2} \mathrm{CO}$ & $\mathrm{H}_{2} \mathrm{NCN}$ & $\mathrm{HC}_{4} \mathrm{~N}$ & & & & & \\
\hline $\mathrm{NH}$ & HNO & $\mathrm{H}_{2} \mathrm{CN}$ & $\mathrm{HNC}_{3}$ & $c-H_{2} C_{3} \mathrm{O}$ & & & & & \\
\hline $\mathrm{NO}$ & $\mathrm{MgNC}$ & $\mathrm{H}_{3} \mathrm{O}^{+}$ & $\mathrm{H}_{2} \mathrm{COH}^{+}$ & $\mathrm{C}_{5} \mathrm{~N}^{-}$ & & & & & \\
\hline $\mathrm{NaCl}$ & $\mathrm{N}_{2} \mathrm{H}^{+}$ & $c-S_{i} C_{3}$ & $\mathrm{C}_{4} \mathrm{H}^{-}$ & & & & & & \\
\hline $\mathrm{OH}$ & $\mathrm{N}_{2} \mathrm{O}$ & $\mathrm{CH}_{3}^{v}$ & $\mathrm{HC}(\mathrm{O}) \mathrm{CN}$ & & & & & & \\
\hline $\mathrm{PN}$ & $\mathrm{NaCN}$ & $\mathrm{C}_{3} \mathrm{~N}^{-}$ & & & & & & & \\
\hline SO & OCS & $\mathrm{PH}_{3}(?)$ & & & & & & & \\
\hline $\mathrm{SO}^{+}$ & $\mathrm{SO}_{2}$ & HCNO & & & & & & & \\
\hline $\mathrm{SiN}$ & $c-S i C_{2}$ & $\mathrm{HOCN}$ & & & & & & & \\
\hline $\mathrm{SiO}$ & $\mathrm{CO}_{2}^{v}$ & $\mathrm{HSCN}$ & & & & & & & \\
\hline $\mathrm{SiS}$ & $\mathrm{NH}_{2}$ & $\mathrm{H}_{2} \mathrm{O}_{2}$ & & & & & & & \\
\hline $\mathrm{CS}$ & $\mathrm{H}_{3}^{+v}$ & & & & & & & & \\
\hline $\mathrm{HF}$ & $\mathrm{SiCN}$ & & & & & & & & \\
\hline $\mathrm{FeO}(?)$ & AlNC & & & & & & & & \\
\hline $\mathrm{O}_{2}$ & SiNC & & & & & & & & \\
\hline $\mathrm{CF}^{+}$ & $\mathrm{HCP}$ & & & & & & & & \\
\hline $\mathrm{SiH}(?)$ & $\mathrm{CCP}$ & & & & & & & & \\
\hline $\mathrm{PO}$ & $\mathrm{AlOH}$ & & & & & & & & \\
\hline $\mathrm{AlO}$ & $\mathrm{H}_{2} \mathrm{O}^{+}$ & & & & & & & & \\
\hline $\mathrm{OH}^{+}$ & $\mathrm{H}_{2} \mathrm{Cl}^{+} 6$ & & & & & & & & \\
\hline $\mathrm{CN}^{-}$ & $\mathrm{KCN}$ & & & & & & & & \\
\hline $\mathrm{SH}^{+}$ & $\mathrm{FeCN}$ & & & & & & & & \\
\hline
\end{tabular}

particularly steep and linked to the crop of light hydrides harvested by HERSCHEL, a space telescope that opened, after ISO and SPITZER, the mid-IR, far-IR and sub-mm domains to high sensitivity observations. The advent of ALMA, which yields an unprecedented leap in sensitivity and angular resolution throughout the sub- $\mathrm{mm}$ and $\mathrm{mm}$-wave bands $(0.3 \mathrm{~mm}$ to $4 \mathrm{~mm})$ will undoubtedly bring a rich crop of new molecules. ALMA's angular resolution will be particularly interesting for resolving individual protostellar cores, protoplanetary disks and cometary heads, which will help solving the problem of spectral line confusion in the quest for prebiotic molecules (see [11]).

Obviously, the cost and complexity of new facilities increases much faster than the curve of Fig. 11, making it more and more difficult to finance and construct new instruments. While, until the late 1970's, radio telescopes were mostly built and owned by regional Observatories and Universities (e.g. FCRAO and CSO), they became national, bi-national in the 80's (JCMT and the IRAM 30-m telescope, as well as PdBI, now being expanded as NOEMA, a French-German-Spanish project, to twelve 15-m diameter antennas) and continental in mid 90's (EVN, VLBA). The HERSCHEL mission (2009) was jointly set up by Europe and the United States, whereas the newest observatory, ALMA, is a worldwide project: its 
construction involves a score of countries from 4 continents with, as biggest players, Canada, France, Germany, Great Britain, Japan, Netherland and USA, as well as Chile, which hosts the instrument. ALMA is a mammoth project by its size: 66 high surface-accuracy antennas, spread over a $16 \mathrm{~km}$ wide area on a higher site than any other ground-based observatory (5000 $\mathrm{m}$ altitude!) for a cost close to 1 billion euros.

Considering that over 14 different languages, including Chinese, English, French, German, Japanese, Russian and Spanish, are put to use for the construction of ALMA we come close to the erection of a second Tower of Babel. Obviously, the quest remains the same: the origins of light and life in the cosmos. Let's hope astronomers will be more successful than the ancients of Mythic Babylon.

\section{References}

[1] Allamandola, L.T., Tielens, A. G., Barker, J.R., Ap. J. 290, p. L25, 1985

[2] Buhl, D. \& Snyder, L., Nature 228, p. 267, 1969

[3] Cami, J., Bernard-Salas, J., Peeters, E., Malek, S.E., Science 329, p. 1180, 2010

[4] Carruthers, G. R., Ap. J. 161, L61, 1970

[5] Cheung et al. Phys. Rev. Letters 21, 1701, 1968

[6] Cheung et al. Nature 221, p. 626, 1969

[7] Cologne Data Basis for Molecular Spectroscopy, Holger S.P. Müller et al. http://www.astro.unikoeln.de

[8] Douglas, A. \& Herzberg, G., Ap. J 94, 1941, p. 381

[9] Douglas, A.E. Nature 269, p. 130

[10] Green, S., Montgomery, Thaddeus, P., Ap. J. 93, L89, 1974

[11] Guélin, Combes, Brouillet \& Wooten, 2007

[12] Guélin, Friberg, Mezaoui 1982, A\&A 109, 23

[13] Guélin, Green \& Thaddeus 1978, Ap. J. 224, L27

[14] Guélin \& Thaddeus 1976, Ap. J. 212, L81

[15] Hoyle, F. The Dark Cloud, Penguin Books, 1969

[16] Kawaguchi, K. et al., Ap. J. 406, L39, 1993

[17] Kroto, Smaley, Curl, Nature 318, 1984, p. 162

[18] Kroto and Walton 1975

[19] Léger, A., Pujet, J.L. A\&A 137, L5, 1984

[20] Loiseau et al., A\&A 466, 999, 2007

[21] Merrill \& Wilson, Ap. J. 87, 1938, p.9

[22] McKellar, PASP 1940

[23] Sheldon Green, Montgomery and Thaddeus, Ap. J. 93, 1938, L89

[24] Snyder, L.E., Buhl, D., Zuckerman, B., and Palmer, P. Phys. Rev. Lett. 22, p. 679, 1969

[25] Swings, P. \& Rosenfeld, L. Ap.J. 86, p. 483, 1937

[26] Thaddeus, P., Phil. Trans. R. Soc. B 361, 1681-1687, 2006

[27] Townes, C.H., Schawlow, A.L. Microwave Spectroscopy, Dover, 1975

[28] Tucker, K.D., Kutner, M.L., Thaddeus, P., Ap. J. 193, p. 115, 1974

[29] Weinreb, S. et al., Nature 200, p. 829, 1963

[30] Wilson, R., Jefferts, K. Penzias, A., Ap. J 161, L43, 1970 